\title{
Progress on larval and juvenile nutrition to improve the quality and health of seawater fish: a review
}

\author{
Toshio Takeuchi
}

Received: 3 October 2013/Accepted: 1 April 2014/Published online: 30 April 2014

(C) The Author(s) 2014. This article is published with open access at Springerlink.com

\begin{abstract}
In seedling production of seawater fish, providing appropriate nutrition is a necessity for successful production of quality larvae and juveniles. Mass-produced live prey organisms, such as the rotifer Brachionus plicatilis species complex and brine shrimp Artemia spp., alone do not provide sufficient nutrition to the larvae and juveniles of seawater animals. This inadequacy has led to various problems related to fish quality and health, including increased incidence of morphological and behavioral abnormalities and mass mortalities. It is, therefore, important to identify the factors associated with these problems to improve seedling production techniques. This review collates the efforts made during the past two decades in larval nutrition-focusing on advances made in the use of certain nutrients, such as docosahexaenoic acid, vitamin A derivatives, and taurine that are important for the mass production of seawater fish larvae and juveniles-with an aim to improve the quality and health of fish.
\end{abstract}

Keywords DHA $\cdot$ Juvenile $\cdot$ Larvae $\cdot$ Nutrition $\cdot$ Seed production $\cdot$ Taurine $\cdot$ VA

\section{Introduction}

In 2006, Worm et al. [1] demonstrated in an alarming article the prediction that world marine resources would be

This article publication is sponsored by the Japan Society for the Promotion of Science (JSPS) in a Grant-in-Aid for Publication of Scientific Research Results (KAKENHI 252018).

T. Takeuchi $(\bowtie)$

Tokyo University of Marine Science and Technology, Konan,

Minato, Tokyo 108-8477, Japan

e-mail: take@kaiyodai.ac.jp exhausted by 2048. Since then, declining populations of marine animals, such as bluefin tuna and eel, have been reported one after another, making the Science article more and more realistic. At the same time, the demand for marine products, as demonstrated by annual per capita consumption of seafood products, has been increasing in the United States, Europe, East Asia, and especially in China where the quantity supplied increased from $7 \%$ in 1961 to $35 \%$ in 2010 [2]. Given these circumstances, the global fishing industry has made a transition from fishing to farming. Consequently, the production of edible fish from aquaculture has reached $47 \%$ of the total fish production in 2010. One of the techniques essential to supporting the aquaculture industry is artificial seedling production.

Although artificial seedling production in the freshwater aquaculture sector has been practiced since the first half of the 20th century, it was only sometime in the 1960s that the seawater sector started practicing artificial seedling production. Seedling production consists of fertilized egg collection and the three types of biological production: the breeding of larval and juvenile fish, cultivation of prey organisms, and cultivation of algae (as feed for prey animals). The difficulty in mass-producing prey animals for larval and juvenile fish in large supply and the low nutritional value of the mass-produced prey animals were the major reasons for the particularly late start of the seedling production of seawater fish. However, with marked advances in aquaculture technology in recent years, Japan currently produces 1-10 million of seawater fish seeds per hatchery.

A live prey schedule containing Brachionus plicatilis sp. complex (hereafter referred to as rotifer) and brine shrimp Artemia larva (hereafter referred to as Artemia) is used for the production of most seawater fish seeds. Thus, the use of bivalve larvae and copepods (such as Tigriopus or Acartia) is rare today, with the exception of the planktonic crustacean 
Daphnia, which is still frequently used in addition to the formulated diet in the production of freshwater fish seeds. Due to the discovery that baking yeast is an excellent feed for rotifers in culture, it became possible to increase the growth density of rotifers from 40 to 60 rotifers $/ \mathrm{ml}$ of culture water, achieved previously with chlorella, to 400-600 rotifers $/ \mathrm{ml}$. Subsequently, the use of yeast in culturing rotifers became widespread in response to mass seedling production [3]. However, larval and juvenile fishes that were reared on a diet of rotifers fed yeast exhibited a slow reaction time to stimuli, and there were many reports of significant abdominal buoyancy as well as the complete mortality of seawater fish, such as red sea bream and parrot fish, about 10 days after initiation of feeding. Conversely, when only Artemia was continuous given as feed, mass mortality occurred in a much larger population of fishes, and even when no mortality occurred fishes showed a lack of energy, with different species affected to varying degrees. Comprehensive investigation to determine whether mass mortality in larval and juvenile fishes was due to nutritional deficiency revealed that many live feeds were ,indeed, nutritionally incomplete. In particular, the lack of n-3 highly unsaturated fatty acid (n-3 HUFA) with docosahexaenoic acid (DHA), both of which are essential fatty acids for seawater fishes, was the cause of mass mortality associated with the diets containing rotifers fed yeast or Artemia [3]. In addition, it became clear that the dietary requirement for DHA varies among seawater fish species. Consequently, feeds for seed production today are sampled prior to feeding to ensure adequate amounts of nutrients, particularly taurine and DHA.

Conventionally, the research and development of seedling production technology aimed to quantitatively increase seed production. However, along with this quantitative expansion, it became clear that when artificially produced seeds are used for fish stocking and farming, recovery rates suffered a decline and farming outcomes are affected unless fish health (physiological and morphological conditions) and fish quality (environmental adaptability to the place of stocking and farming) are improved [4]. These findings led to an increase in the demand for healthy and high-quality seeds and shifted the focus of the research and development of seedling production technology from quantitative expansion to quality improvement.

In this review, with the aim of improving the quality of seedling production, we summarize recent findings on DHA, vitamin A-related substances, and taurine, all of which are vital nutrients for fish.

\section{Docosahexaenoic acid and quality of larvae and juveniles of seawater fish}

As we know, the fatty acid compositions of traditional live foods (e.g., rotifer and Artemia) reflect the food supply in their mass production. One of the disadvantages of these commercially produced live foods is the low content of $n-3$ highly unsaturated fatty acid (n-3 HUFA) [5, 6]. In particular, docosahexaenoic acid (DHA, 22:6n-3) is the most important n-3 HUFA for larvae and juveniles of seawater fish, and a high concentration of DHA in rotifer and Artemia has been shown to be essential for the seed production of yellowtail Seriola quinqueradiata, red sea bream Pagrus major, and striped jack Pseudocaranx dentex [7]. This section of the review discusses the importance of DHA.

\section{Post-hatching changes in DHA content in seawater fish}

The body fatty acid composition of seawater fish changes after hatching. In newly hatched fed larvae, the percentage of DHA (the composition ratio of DHA that originated from the egg relative to all fatty acids) decreases sharply over the first 10 days or so after hatching in yellowtail, red sea bream, flounder Paralichthys olivaceus, striped jack, and Pacific cod Gadus macrocephalus fed rotifer, as well as in common octopus Octopus vulgaris fed Artemia (Fig. 1) [8]. During this period, the body weight of fish sharply increases while the lipid content decreases. For example, in Pacific cod there is a dramatic decrease in the DHA content: the amount of DHA per gram wet weight on day 15 dropped to $1.2 \mathrm{mg} / \mathrm{g}$, one-fifth of the initial amounts $(6.1 \mathrm{mg} / \mathrm{g}$ on post-hatching day 1); and the absolute amounts down to $1.7 \mu \mathrm{g} / \mathrm{fish}$, one-half of the initial amounts $(3.7 \mu \mathrm{g} / \mathrm{fish})$. We can rule out a possibility of the changes in DHA during post-hatching as a result of fasting

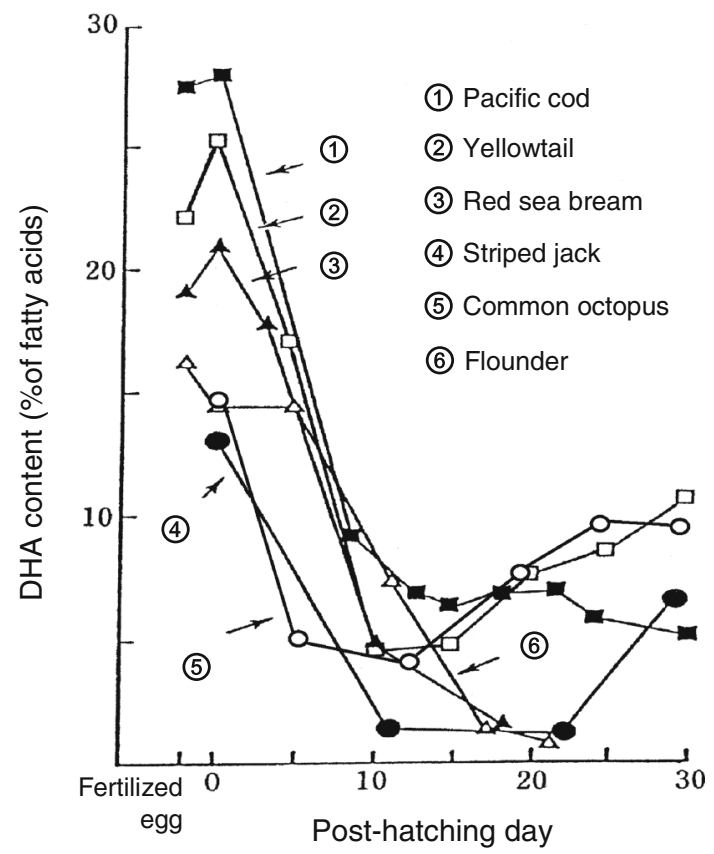

Fig. 1 Change in the DHA content in different seawater fish hatchlings [8] 
condition in the hatchling. Usually in the fasted fish, the percentage of certain fatty acids such as arachidonic acid (20:4n-6) and DHA increase due to decreased body fat, whereas saturated and monounsaturated fatty acids decrease, even in an absolute amount, most prominently in neutral lipid, as they are consumed for energy $[9,10]$. On account of the fact that the fatty acid compositions in newly hatched fed larvae reflect the food supply, the quick decrease of the DHA content in both polar and neutral lipids may suggest insufficient dietary DHA content, especially during the post-hatching period.

\section{Live food quality in relation to DHA}

Studies on the effect of the essential fatty acids eicosapentaenoic acid (EPA, 20:5n-3) and DHA during the Artemia-feeding period have revealed that yellowtail and striped jack have a higher DHA requirement than red sea bream and flounder [7]. Interestingly, in a "vitality test" where the larvae were exposed to the air for 5-20 s in a scoop net before being returned to the culture tank, only DHA-fed larvae showed a favorable survival rate (usually after 24 h). Artemia, regardless of origin, contain no DHA. In fish fed Artemia enriched with high-purity DHA ethyl ester, DHA is converted to docosapentaenoic acid (22:5n3) [11] and EPA or used as an energy source. Consequently, the DHA-enrichment effect obtained with DHA ethyl ester is only one-third of that obtained with the same amount of EPA. These findings indicate that the low DHA content in live foods is likely to be one cause of the mass mortality of red sea bream larvae immediately after transfer to a net cage and for the low survival rate of yellowtail and striped jack during seed production.

The nutritional enrichment of live foods containing dried shark eggs is a possible solution for increasing the dietary content of DHA [12-14]. The fins of the spiny dogfish Squalus acanthias are used as food products, and the eggs from the captured sharks are obtained as a byproduct. To ensure efficient by-product use, the eggs can be processed into dried powder and used to nutritionally enrich rotifer and Artemia with high concentrations of EPA and DHA. The mixture consists of roughly equal amounts of protein and lipid per dry weight and contains $3.9 \%$ EPA, $7.6 \%$ DHA [7], and $0.5 \%$ taurine. Subsequent studies have demonstrated the utility of this shark egg powder not only as an enrichment material, but also as a paste feed for leptocephalus, the larvae of eel [15].

The DHA content required for live foods, especially Artemia, varies among fish species; the highest concentration is required by yellowtail and striped jack, followed by Pacific cod, red sea bream, and flounder [16]. In nutritionally enriched live foods, the DHA concentration varies substantially depending on the viability, strain, and enrichment procedures of the live foods such as water temperature, enrichment duration, enrichment concentration, and aeration intensity. Close attention is, therefore, needed when nutritionally enriching rotifer and Artemia for fish with a high DHA requirement.

Effects of dietary DHA on larvae and juveniles of seawater fish

The relationship between the content of highly unsaturated fatty acids (e.g., DHA) in live foods and fish health (e.g., normal morphology rate) has been investigated in flatfish such as flounder [7], marbled sole [17], turbot [18], and brown sole Pseudopleuronectes herzensteini [19, 20]. A recent study on brown sole showed that an increased DHA content (from $0.6 \%$ to $1.7-3.2 \%$ ) in rotifer between post-hatching days 15 and 25 (stages D to F) significantly improved survival and normal morphology rates, demonstrating that DHA supplementation is particularly beneficial during the metamorphic period known as the DHA-sensitive period (Fig. 2) [21]. The following details the investigation in some species of seawater fish (e.g., yellowtail and octopus).

\section{Yellowtail}

The reduced quality of released yellowtail juveniles is an ongoing problem. A previous study has shown that red sea bream reared in a net cage at a low population density do not exhibit schooling behavior but rather lying behavior as seen in wild individuals [22]. Another study has shown that wild and hatchery flounder exhibit distinct feeding behavior; the former show quick movement while the latter show slower off-bottom movement [23].

DHA has been shown to have a major effect on the vitality and behavior of larval and juvenile yellowtail. When yellowtail larvae and juveniles fed Artemia enriched with oleic acid (OA), EPA, or DHA, they were observed to exhibit dispersion, aggregation, and inherent schooling behavior, respectively [24, 25]. More specifically, the nearest neighbor angle decreased gradually only in the DHA-fed fish, indicating that the larvae were swimming in the same direction, while an increased nearest neighbor distance was observed in the OA-fed fish compared with the EPA-fed and DHA-fed fish, indicating a greater distance between individuals (Fig. 3).

A study to elucidate the reason for these behavioral differences revealed, from a comparison of the size of different parts of the brain, accelerated (retarded) development of the optic tectum and cerebellum in the DHA (OA)-fed fish [26]. Another study using [14] C-DHA to determine the distribution of DHA in the fish brain revealed an increased distribution of DHA in the periventricular gray and central white layers (nerve fiber 


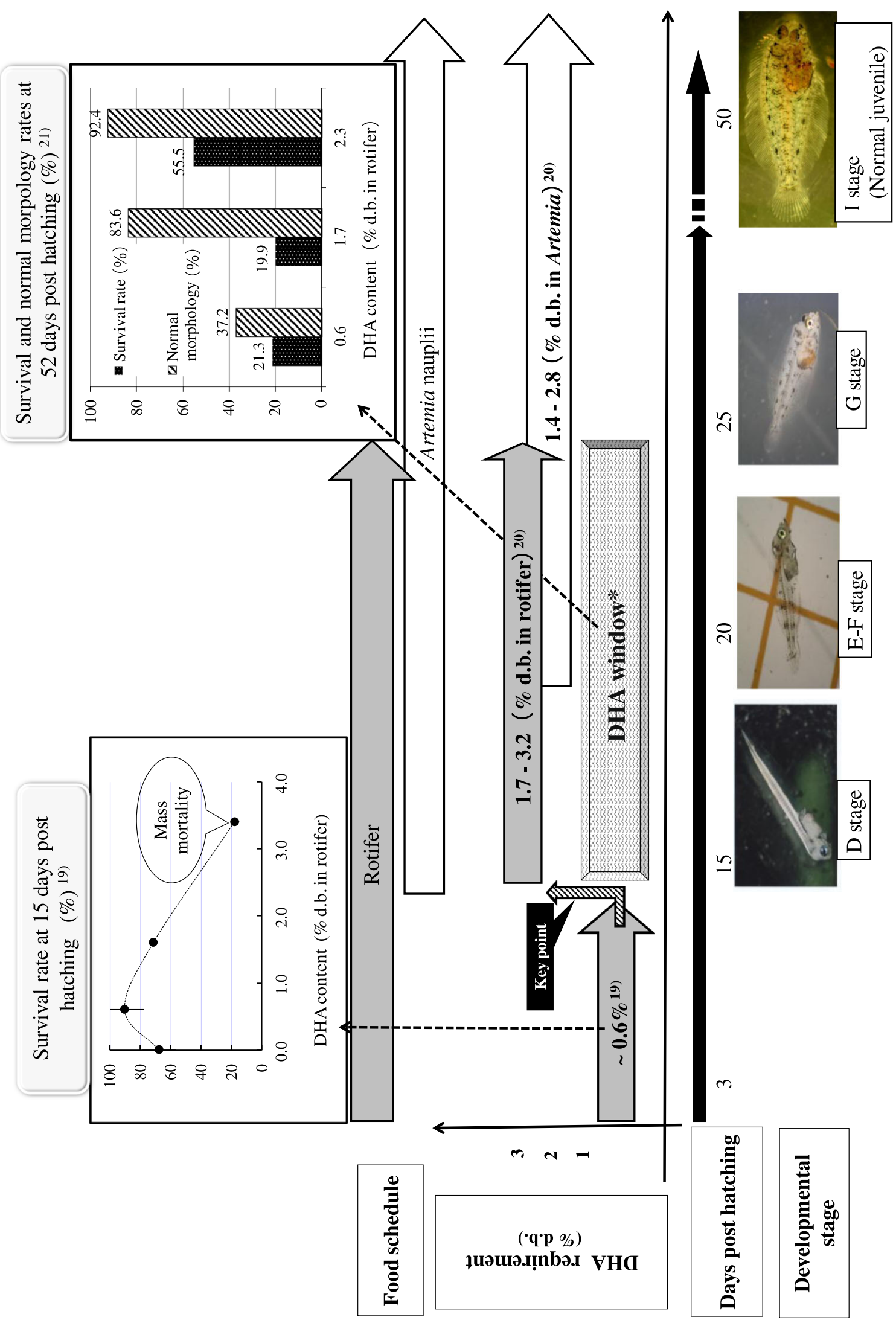

Fig. 2 Schematic representation of DHA nutritional requirements for larvae of brown sole Pseudopleuronectes hersensteini. Asterisk indicates the rearing period when DHA nutrition is considered critical [21] 


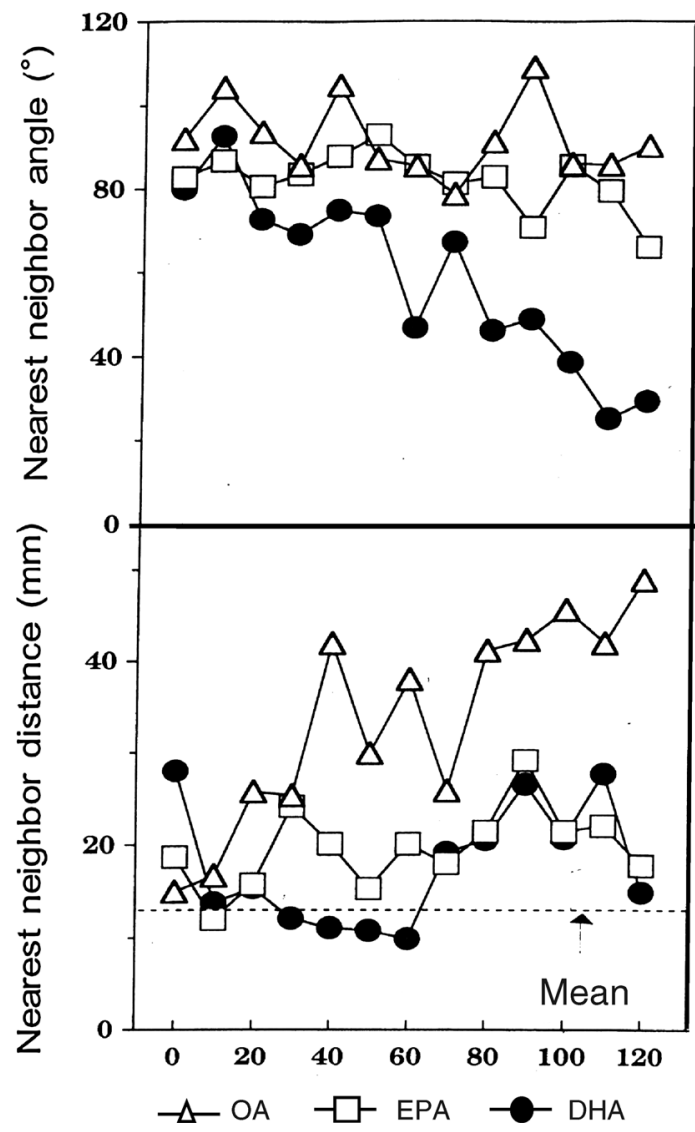

Fig. 3 Effect of dietary fatty acids including DHA on the orientation of free-swimming juvenile of yellowtail Seriola quinqueradiata. The fish positions are mapped over a period of $120 \mathrm{~min}$ and presented in terms of distances or angle between adjacent juvenile. Nearest neighbor angle (NNA) indicates the angle formed by adjacent individuals; $\mathrm{NNA}=0^{\circ}$ indicates fish oriented in the same direction, $\mathrm{NNA}=90^{\circ}$ indicates they are swimming in different directions. Nearest neighbor distance indicates the distance between adjacent individuals, with a lower value indicating increased school formation

layer) of the optic tectum and granular layer (nerve cell layer) of the cerebellum [27]. These observations suggest that dietary DHA intake by yellowtail larvae leads to the growth of nerve cells in the optic tectum and cerebellum, the extension of dendrites, and the creation of an information network through synapses at the tips of extended dendrites. Such development of the visual and motor centers might allow fish that would exhibit only the low-order behavior of taxis without supplementation to exhibit the higher-order behavior of schooling with it. Thus, DHA is involved not only in the development of vision, but also in the construction of higher-order neural networks that govern, for example, the development of swimming ability [28]. These results may reflect the essentiality of DHA to "better working of the brain", as demonstrated in rodents where DHA intake leads to an improved learning effect.

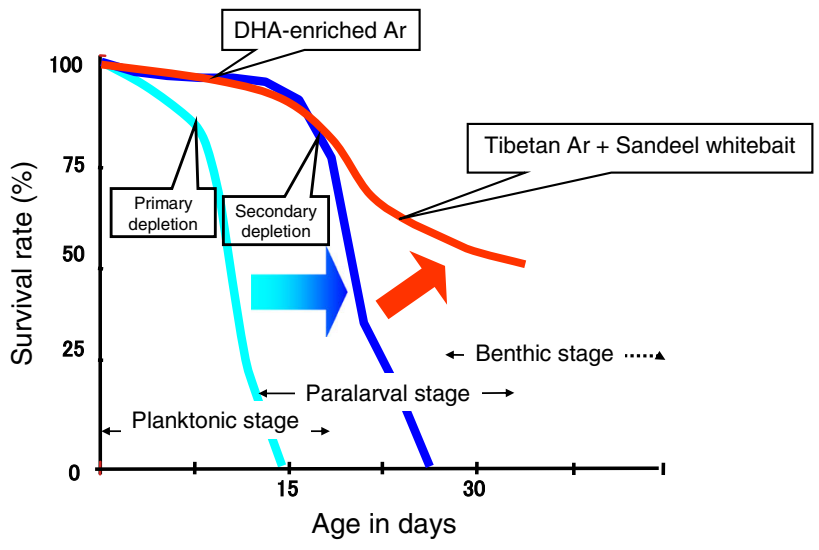

Fig. 4 Dietary DHA requirement to prevent primary and secondary losses of octopus Octopus vulgaris during their larval rearing. Note that larvae receiving DHA enriched Artemia has improved survival rate [29]. Ar indicates Artemia

\section{Common octopus}

Studies have revealed that insufficient dietary DHA intake is responsible for the initial mass depletion of planktonic common octopus larvae observed up to around 10 days after hatching (Fig. 4) [29]. Newly hatched octopus have short arms with 3-4 suckers and are planktonic, unlike adults. The number of suckers increases as the arms grow, and after 18 suckers have formed (28 days after hatching), the animals become benthic. During seed production of the common octopus, the number of newly hatched larvae starts to decrease rapidly around 1 week after hatching and most have died by around 15 days after hatching. At this time, adult Artemia is given as the initial feed; however, this feed is difficult to nutritionally enrich and its nutritional value quickly decreases [7]. Experiments have demonstrated the effectiveness of enriched foods by direct addition of nutrients such as shark eggs, lipid materials, and DHA algae to the culture tank and have also revealed a positive correlation between DHA content in Artemia and survival rate and the numbers of suckers [30]. These results have proven valuable in helping prevent the depletion of planktonic octopus paralarvae by maintaining a certain level of DHA in Artemia.

The common octopus suffers a secondary depletion, however, around 15-25 days after hatching, which must be prevented to obtain benthic juvenile octopus with $\geq 18$ suckers (i.e., settling octopus). Although the experimental results above suggest the benefit of DHA supplementation, it is difficult to provide sufficient amounts of DHA through the nutritional enrichment of adult Artemia. Investigators have, therefore, looked at using sandeel whitebait instead, based on the knowledge that many wild common octopus 
paralarvae are captured with anchovy whitebait during seine boat fishing for whitebait, which suggests that the paralarvae fed on whitebait [31]. Subsequent studies have demonstrated better results with sandeel whitebait than with anchovy whitebait, and the addition of sandeel whitebait flakes containing large amounts of EPA and DHA directly to the culture tank has proven even more effective for rearing [32]. As another alternative, nutritionally enriched Artemia nauplii in place of adult Artemia were used. When common octopus paralarvae were fed Tibetan Artemia, North American Artemia (Utah strain produced from Great Salt Lake, US), which is routinely used in seed production), or Tianjin Artemia enriched with shark eggs and with or lacking sandeel whitebait, favorable results were obtained only in those animals fed the Tibetan Artemia plus sandeel whitebait. Thus, it would appear that only the combination of shark egg-enriched Tibetan Artemia plus sandeel whitebait is effective for preventing the secondary depletion [33]. However, the difficulties in routinely procuring Tibetan Artemia and in ensuring its sufficient quality (e.g., its hatching rate is variable) further complicates its use.

Working on the premise that if we can identify which ingredients of Tibetan Artemia are beneficial to common octopus larvae, it should be possible to sufficiently enrich Artemia of any origin, investigators began looking for these nutritional ingredients. It has been found that feeding with North American Artemia enriched with lipid, polar lipid in particular, results in an increased number of suckers, body weight, and survival rate, suggesting that polar lipids contain beneficial ingredients [34]. The identification and practical application of these ingredients should allow for mass seed production of the common octopus paralarvae.

\section{DHA overdose}

Previous studies have shown that rainbow trout fed diets supplemented with high concentrations of essential fatty acids such as EPA and DHA showed reduced growth and feed efficiency [35]. Similar effects have also been observed in seawater fish larvae. In the seed production of Pacific cod and brown sole, rotifer containing $3 \%$ or higher concentrations of DHA resulted in mass mortality $[13,19]$, presumably as a direct effect of DHA overdose. Moreover, in the seed production of Scylla serrata, a species of mud crab, excessive dietary levels of n-3HUFA and DHA have led to failed molting and morphological abnormalities, such as seta formation, in zoea [36, 37]. These observations suggest that an appropriate concentration of DHA in live foods is essential to improving the quality of seawater fish.

\section{Vitamin A and larval quality}

Flounder is one of the most popular fish species produced through seed production in Japan. Although established seed production procedures have enabled the mass production of up to one million flounders per facility, the occurrence of skeletal anomalies, pseudo albinism, and hypermelanosis on the blind side has reduced the survival of released individuals and the market price of caught individuals [23, 38]. More specifically, skeletal anomalies include malformations of the maxilla, mandible, caudal peduncle, and fin rays, and fused or wavy vertebrae. Pseudo albinism is the partial whitening of the body surface on the ocular side resulting from failed pigmentation at the end of metamorphosis, and hypermelanosis on the blind side is the partial or total pigmentation of the body surface on the normally white blind side.

\section{History of preventing malformations}

Since the 1980s, many reports have indicated the preventive and exterminating effects of early stage feeds on pseudo albinism in P. olivaceus. Early life stage feeding of Artemia and a diet of Brazilian Artemia has led to a high incidence of pseudo albinism, whereas feeding wild zooplankton, fertilized red sea bream eggs, and vitamin A-supplemented rotifer has reduced the incidence [39-43]. It was later reported that vitamin A, DHA, and phospholipids are necessary for normal pigmentation on the ocular side [17]. However, feeding vitamin A-enriched rotifer was found to lead to a high incidence of elongated caudal peduncles, partial loss of caudal fin rays, limited growth, and malformed caudal vertebrae. It thus became clear that vitamin A supplementation for preventing pseudo albinism causes skeletal anomalies [44, 45].

These abnormalities are thought to occur in certain sensitive stages in the development of flounder larvae [46]. According to Minami et al. [47], flounder have nine developmental stages (A-I), ranging from larvae to juveniles. This staging system has been adopted by many investigators as a useful tool for understanding the early stage life cycle and morphogenesis of flounder. In particular, the period between late stage $\mathrm{D}$ and stage $\mathrm{E}$ is important for the determination of pseudoalbinism [48].

\section{Effects of vitamin A derivatives}

Many studies conducted in the 1990s on vitamin A and vitamin A-related abnormalities suggested the impact of feeding concentration/stage and immersion concentration/ stage (Fig. 5) [49]. Early studies reported rotifer enriched with vitamin $\mathrm{A}$ at a concentration of 50,000 IU/L in culture medium prevented pseudoalbinism but not skeletal 
Fig. 5 Pictograph summarizing different studies that examined the effect of vitamin A and its derivatives on the development of flounder Paralichthys olivaceus. The anomalies reported in the different studies are mentioned in the different boxes. The amount of vitamin provided for the fish are indicated on the $x$ axis

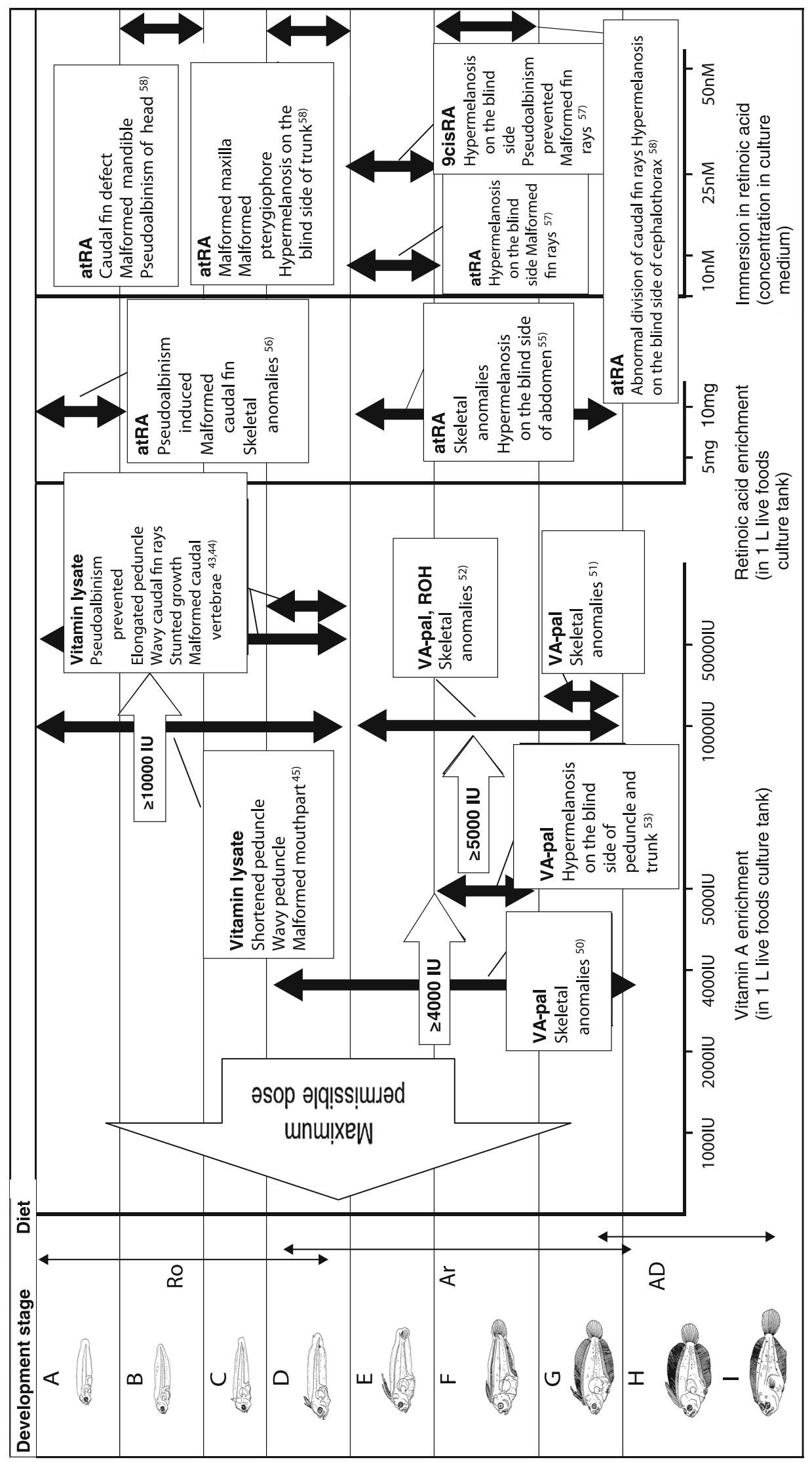


malformations, which were observed even at a much lower vitamin A concentration of 10,000 IU/L [44, 45]. When Artemia was used, the addition of vitamin A at concentration of $\geq 4,000 \mathrm{IU} / \mathrm{L}$ in culture medium caused vertebral anomalies, and the threshold dose of vitamin $\mathrm{A}$ to avoid vertebral anomalies was determined to be 2,000 IU/L [50]. These findings suggest that vitamin A-enriched Artemia is more likely to cause skeletal anomalies at lower vitamin A concentrations than vitamin A-enriched rotifer; we will return to the reason for this later in this section. Another study showed that feeding flounder larvae with Artemia enriched with 10,000 IU/L vitamin A for only 2-3 days caused vertebral anomalies [51]. Similarly, feeding stage E-H flounder larvae with Artemia enriched with vitamin A derivatives, such as ester-type vitamin A palmitate, retinol, retinoic acid, and vitamin $\mathrm{A}$ acetate, resulted in a high incidence of vertebral anomalies. In fact, retinoic acid, an active form of vitamin A, is present in all Artemia enriched with vitamin A derivatives [52].

In regard to hypermelanosis on the blind side, flounder larvae fed Artemia enriched with $\geq 5,000$ IU/L vitamin A palmitate only for 5 days during stages F-G developed the disorder. Retinoic acid was detected in these Artemia at a level of 7.2-20.5 $\mu \mathrm{g} / \mathrm{g}$, dry basis (d.b.) [53]. Analysis of the kinetics of vitamin A-enriched live foods revealed that vitamin A palmitate in rotifer- and Artemia-enriched feed containing 10,000 IU/L vitamin A palmitate was metabolized into retinol and then retinoic acid within around $18 \mathrm{~h}$ after enrichment. The retinoic acid content after $18 \mathrm{~h}$ of enrichment under 2,000 lux illumination was considerably higher in Artemia $(25.6 \mu \mathrm{g} / \mathrm{g}$, d.b.) than in rotifer $(9.6 \mu \mathrm{g} / \mathrm{g}$, d.b.). Thus, more retinoic acid is produced in Artemia after enrichment with the same amount of vitamin A. The previous observations that Artemia was more likely than rotifer to cause skeletal anomalies at a lower concentration of vitamin A appears to be due to the differential retinoic acid levels produced by metabolism in the two types of live foods. A possible contributing factor to this was found in the next study on the effect of photoirradiation during the culture of live foods: light shielding suppressed metabolism to retinoic acid in rotifer but had no effect in Artemia [54].

Flounder larvae fed retinoic acid-enriched Artemia for stages E-H showed a dose-dependent increase in the incidence of vertebral anomalies [55], while larvae fed retinoic acid-enriched rotifer for stages A-B developed pseudoalbinism and malformed caudal fins and vertebrae [56]. More clear-cut results on the effects of retinoic enrichment were obtained when premetamorphic flounder larvae (stages E-F) were immersed in water containing 10 or $25 \mathrm{nM}$ retinoic acid: the larvae developed melanism (with a reduced incidence of albinism) and malformed fin rays [57]. When larvae at different stages of development were immersed in culture water containing $50 \mathrm{nM}$ retinoic acid, larvae at stages B-C developed malformed mandibles and pseudoalbinism of the head, larvae at stages D-E developed malformed maxillae and pterygiophores in addition to hypermelanosis on the blind side of the trunk, and larvae at stages F-G showed excessive caudal fin rays and hypermelanosis on the blind side of the cephalothorax [58].

Based on these findings, the maximum recommended dose of vitamin $\mathrm{A}$ in live foods has been determined as 2,000 IU/L (Fig. 5). It appears that different anomalies are induced by vitamin A derivatives at different developmental stages: skeletal anomalies in stages A-G (from immediately after hatching to immediately before settling on the bottom), albinism in stages $\mathrm{A}-\mathrm{C}, \mathrm{E}$, and $\mathrm{F}$, and melanism in stages E-G. Thus, feeding diets containing a high concentration of vitamin A to larvae at any developmental stage can lead to anomalous development. Moreover, the effect of vitamin A appears to be more evident in immersion studies than in feeding studies. Unlike in immersion studies where larvae are continuously exposed to a consistent concentration of vitamin A, in feeding studies larvae shown a clear sharp increase and decrease in vitamin A content that reflects the dietary intake of vitamin A and its subsequent absorption and metabolism. This is supported by the observation that the concentration of alltrans retinoic acid peaks $3 \mathrm{~h}$ after flounder larvae are fed Artemia enriched with all-trans retinoic acid, before declining to about one-third of the peak concentration $24 \mathrm{~h}$ after feeding [59].

Taken together, the findings to date indicate that retinoic acid, which is produced by metabolizing vitamin A added at high concentration to live foods, is responsible for the occurrence of skeletal and pigmentation abnormalities in flounder.

\section{Other factors}

Apart from vitamin A derivatives, hypermelanosis on the blind side can also be induced in larvae at stage $\mathrm{G}$ by a diet supplemented with vitamin $\mathrm{D}$ at a concentration of 20,000 IU/100 g [60]. However, rearing flounder after settlement in a culture tank with sand has been shown to be effective for preventing the development and progression of hypermelanosis on the blind side [61]. In addition, an analysis of the relationship between pseudoalbinism and the thyroid hormone thyroxin demonstrated that pseudoalbinism can be induced at a high rate simply by exposing flounder larvae at stages E-F to thyroxin by immersion [62].

Attempts have also been made to elucidate our understanding of the molecular mechanism underlying development of pseudoalbinism. Receptor analysis studies [63] 
Fig. 6 Biosynthetic pathways of sulfur-containing amino acids in seawater fish

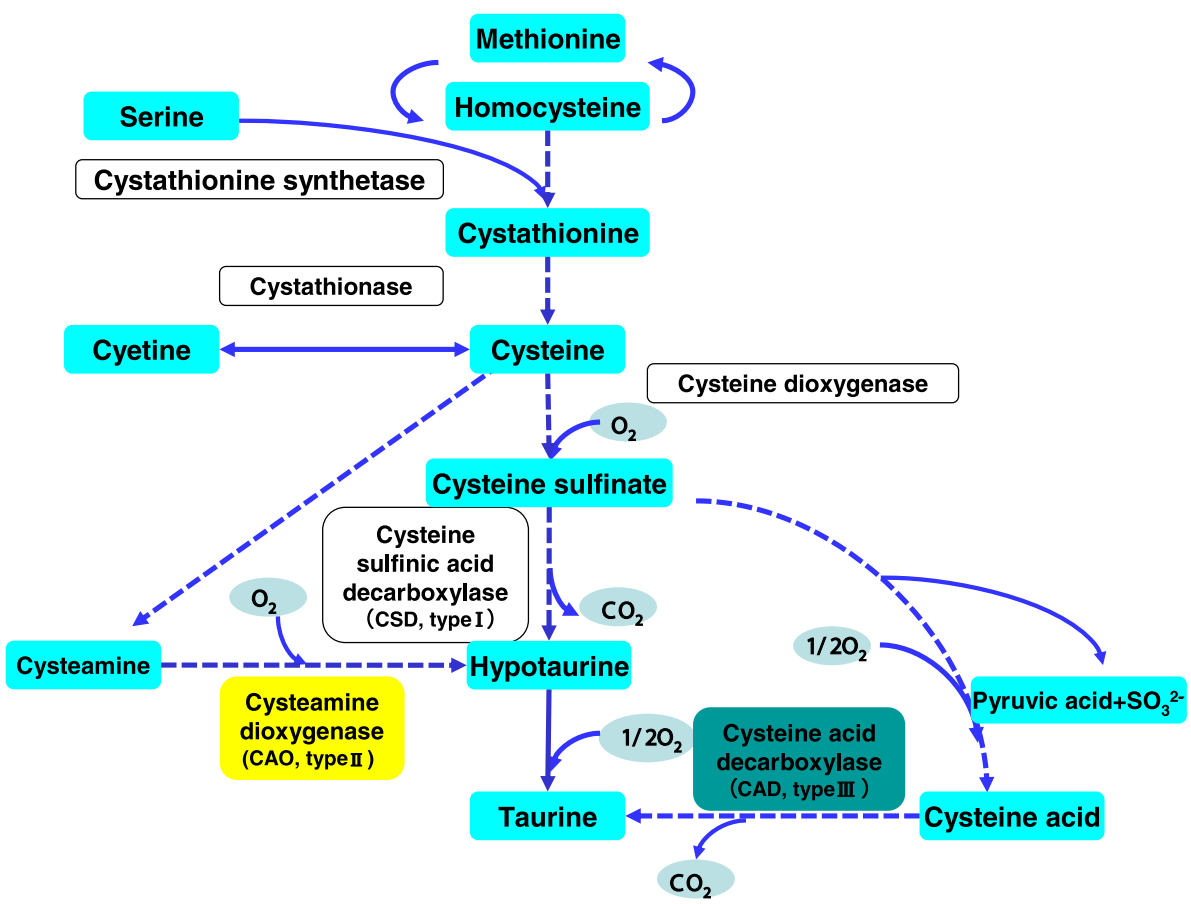

are among the approaches taken so far. Also, a recent review by Hamre et al. [64] reviewed effects of dietary lipid-soluble vitamins on ontogeny of larvae of seawater fish. It is expected that further work will establish seed production techniques that do not rely purely on nutrients given to larval-stage fish but also incorporate research findings from various areas, such as the quality and genetic traits of parent fish.

\section{Taurine and seawater fish quality}

Taurine, or aminoethylsulfonic acid $\left(\mathrm{C}_{2} \mathrm{H}_{7} \mathrm{NO}_{3} \mathrm{~S}\right.$; molecular weight 125.15), is a sulfur-containing amino acid-like compound that can be separated by the same extraction procedure used for regular free amino acids and quantified with an amino acid analyzer [65]. Unlike constituent amino acids, this amino acid-like compound possesses physiological functions, such as prevention of hypertension, improvement of liver function, maintenance of eye function, promotion of energy metabolism, and repair of radiation damage (e.g., suppression of leukopenia).

\section{Taurine biosynthesis}

Taurine is usually biosynthesized from sulfur-containing amino acids, such as methionine, cysteine, and cystine (a cysteine dimer). The metabolic pathway from methionine to taurine is shown in Fig. 6. This pathway involves several enzymes, many of which are in the liver. Cysteine sulfuric acid, an intermediate metabolite, is decarboxylated by cysteine sulfuric acid decarboxylase (CSD) into the taurine precursor hypotaurine, which is then to taurine. Methionine, a source of taurine, is, therefore, regarded as an essential amino acid. When determining whether the required amount of essential amino acids is contained in a given diet, the combined amount of methionine and cystine is calculated. Although animals inherently possess this metabolic pathway, kittens and human infants are not able to synthesize a sufficient amount of taurine from methionine due to low CSD activity and, thus, require taurine as a conditionally essential nutrient. In recent studies, CSD activity was measured in various fish species and found to be high in rainbow trout and tilapia and low in flounder, red sea bream, yellowtail, and bluefin tuna Thunnus orientalis $[66,67]$. It has also been demonstrated that flounder and red sea bream fed a cystine-supplemented diet do not have increased taurine content $[68,69]$.

When the free amino acid content in the body was measured in juvenile flounder, red sea bream, and yellowtail fed taurine-free diets, serine content was increased in the juveniles of all species and cystathionine content was additionally increased in flounder (Fig. 7). This suggests the insufficiency or lack of enzymes involved in the conversion from homocysteine to cystathionine and from cystathionine to cysteine.

\section{Before 1990}

Following the discovery of the taurine requirement of cats in the 1970s, the first study on the taurine requirement of fish was conducted in rainbow trout [70]. In the late 1980s, 
Fig. 7 Comparison of taurine (yellow column), serine (red square) and cystathionine (blue triangle) contents of seawater fish larvae (mean $\pm \mathrm{SD}$, $n \geq 3$ ). T-0, T-0.5, T-1.0, T-1.5 indicate $0,0.5,1.0$ and $1.5 \%$ of taurine supplementation in experimental diets, respectively
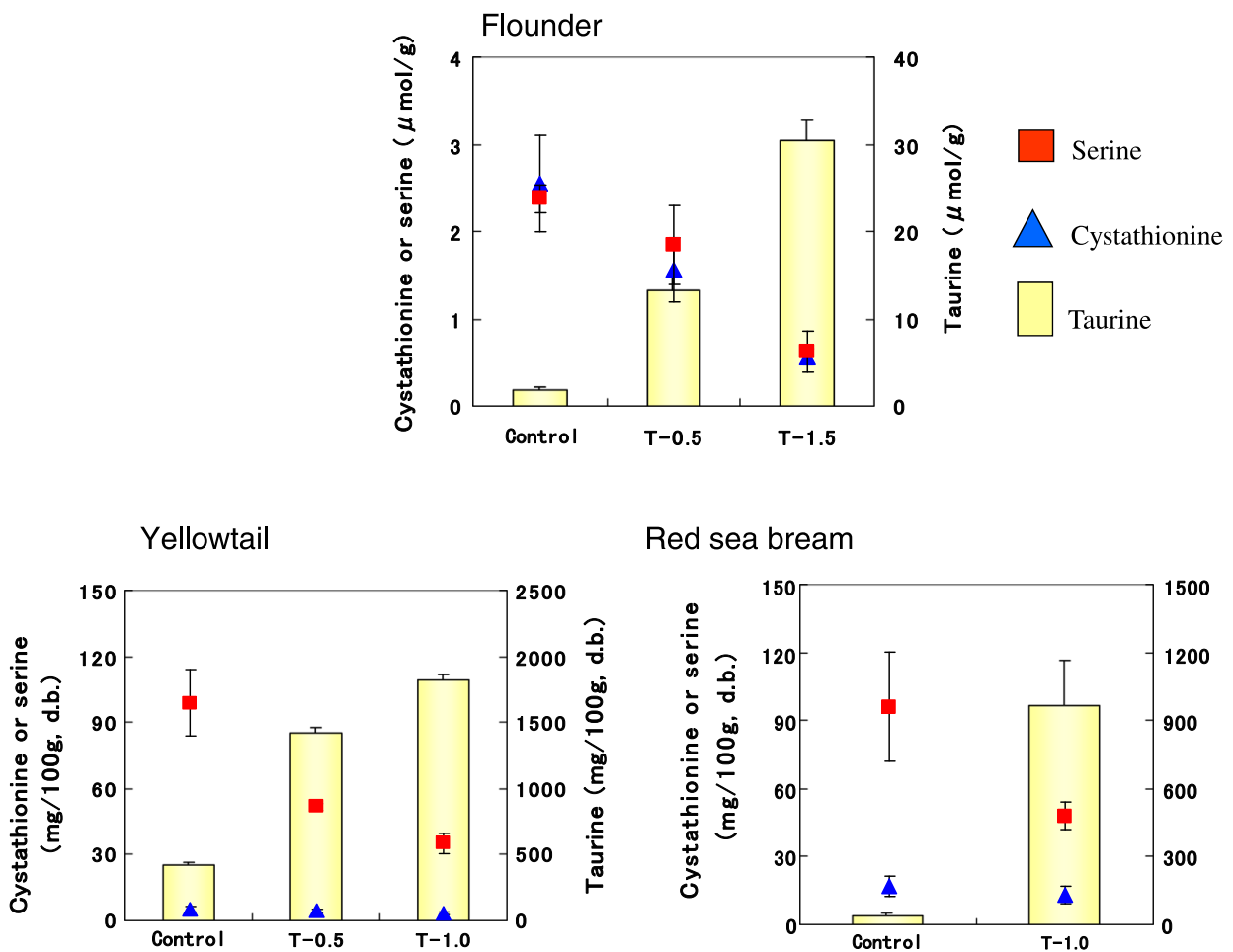

Red sea bream

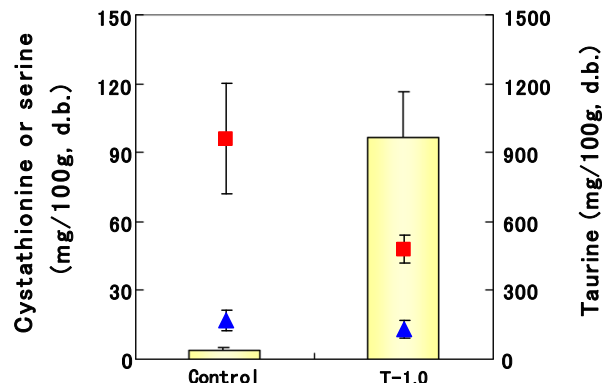

Sakaguchi and Murata reported a slight improvement in the growth in eel and guppy fed taurine-supplemented diets [71], though the news did not attract much attention.

\section{Early 1990s}

In 1992 Yokoyama and Nakazoe [72] concluded that taurine is not required for growth of rainbow trout as the fish can synthesize taurine, and they observed no effect of taurine supplementation in a feeding study.

Meanwhile, as part of the Development of Quality Seed Production Technology Project, a contract research project started in 1991 with the Fisheries Agency, comparative studies began to investigate the quality of hatchery fish and that of wild fish as a control. This project found that wild flounder achieved better growth when fed mysids (Acanthomysis nakazatoi and A. kokuboi) than with a formulated diet for flounder, and that feeding with live mysids resulted in higher n-3 HUFA and taurine levels and lower cystathionine levels in the fish body than feeding with a formulated diet [73, 74]. Given the fact that mysids are rich in taurine, various studies were then carried out to evaluate the effectiveness of taurine enrichment of live foods.

\section{Late 1990s}

Live mysids and dried mysid powder diets for juvenile flounder were produced to identify the diets' active ingredients and it was revealed that dietary supplementation of about $3.5 \%$ taurine is needed to obtain a taurine content in the fish body comparable to that in juveniles immediately after becoming benthic (including wild juveniles). It was also found that after switching from a commercial formulated diet to live mysids, the content of DHA and taurine rapidly increased and reached a constant level within 5 days of switching [75]. These subsequent studies revealed that the active ingredients of mysids consist of free amino acids including taurine, and that the taurine content in commercial diets did not meet the taurine requirement of juvenile flounder [76]. Different patterns of behaviors are exhibited by wild and hatchery juvenile flounder; wild individuals rise up from the bottom to prey for a shorter period than hatchery individuals and are also more likely to turn around while swimming [77]. Of note, juvenile flounder fed a mysid powder diet exhibited a feeding behavior similar to that of wild juveniles [76].

After 2000

Research performed in the 1990s revealed that feeding mysids is effective for promoting the growth of juvenile flounder through the effect of taurine, and that taurine insufficiency is responsible for the development of green liver syndrome, characterized by green discoloration of the liver, in yellowtail and red sea bream fed fish meal-free diets. Following on from this, studies conducted at the start of the 21st century succeeded in determining the actual 


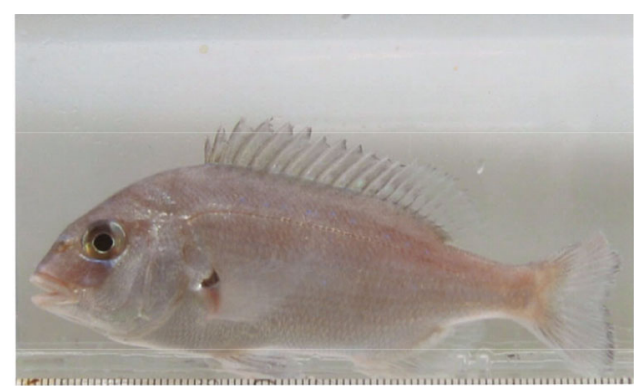

With taurine

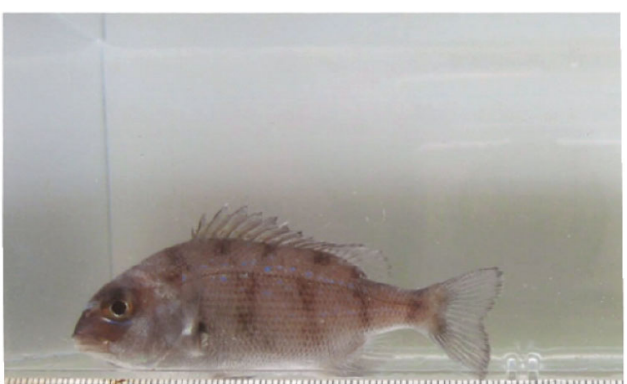

Without taurine

Fig. 8 Pictures of red sea bream Pagrus major juveniles showing differential pigmentation of fish that received diet with or without taurine

taurine requirements of juvenile flounder and red sea bream fed formulated diets.

These studies were able to obtain the optimal growth and feed efficiency at a taurine concentration of $15-20 \mathrm{mg} /$ $\mathrm{g}$ diet [7]. This level is comparable to the taurine content in mysids (the preferred diet of flounder) and corresponds to more than 20 times the taurine requirement of cats $(0.8 \mathrm{mg} /$ g) [78]. Juvenile flounder fed low-taurine diets exhibit relatively slow feeding behavior; they did not rise quickly from the sandy seabed to catch prey and immediately settle back on the sandy bottom, as observed in wild juveniles, but rather after catching prey, they continue to swim near the water surface in search of more prey, much like carp in a pond [79]. Juvenile flounder do not exhibit normal behavior unless fed a diet containing at least $5 \mathrm{mg} / \mathrm{g}$ of taurine. A possible explanation for this abnormal behavior is that the lack of taurine, which is known to be involved in retinogenesis and also functions as a neurotransmitter, leads to difficulty in finding prey and improper transmission of behavioral control. When flounder that do not exhibit normal behavior are released to their natural habitat, they are immediately consumed by predators such as flathead fish (or Ishi-gani Charybdis japonica according to recent reports) and, thus, stocking efficiency decreases.

Juvenile yellowtail fed a fish meal-free diet containing concentrated soy protein as the main ingredient and supplemented with $4.5 \%$ taurine for 39 weeks did not develop green liver syndrome but showed slightly reduced growth compared with those fed a fish meal-containing diet. Green liver syndrome is believed to be caused by failed conjugation of bilirubin and biliverdin by taurine, due to a lack of taurine in the fish body, and the accumulation of these two substances in the liver [80]. The formation of a taurine conjugate requires either glycine or taurine, but in fish only taurine is considered to be involved [81]. These findings indicate that taurine is also conditionally essential in yellowtail [82].

Red sea bream, as well as many other saltwater fish, do not typically eat purified diets where the main ingredient is a protein source used for freshwater fish, such as casein or egg albumin. Moreover, even when they eat these diets, a high growth rate and feed efficiency comparable to those achieved with fish meal-containing diets could not be obtained. The reason for this lack of effectiveness is unclear. Feeding red sea bream a purified taurine-containing casein diet was found to improve growth and feed efficiency, which peaked at a taurine concentration of $\geq 5 \mathrm{mg} / \mathrm{g} \quad(0.5 \%)$ [83]. Moreover, improved feeding behavior and pigmentation (i.e., brilliant pink without darkening, the natural color of the fish) were also observed in individuals fed a diet containing taurine (Fig. 8) [68]. These findings indicate that the previously observed poor growth of saltwater fish was due to the lack of taurine in purified diets and imply the need to review existing studies that have used taurine-supplemented purified diets to examine the deficiencies and requirements of various nutrients in saltwater fish.

\section{Benefit of taurine in seed production}

There is some evidence to support the benefit of taurine in seed production, especially during the rotifer-feeding period. During the initial phase of seed production, larvae are usually fed rotifer. Since rotifer contain only a trace amount of taurine ( $<1 \mathrm{mg} / \mathrm{g}$ dry weight), a rapid decrease in taurine content in the fish body is observed in the hatched larvae of yellowtail, a similar trend to that observed for DHA. When taurine content was measured in hatchery yellowtail larvae and juveniles grown to a body size of up to $18 \mathrm{~cm}$ and in wild yellowtail larvae from 3 to $18 \mathrm{~cm}$, wild larvae contained a taurine concentration 2-4 and 2 times $(15 \mathrm{mg} / \mathrm{g})$ higher than hatchery larvae, respectively; this appeared to be because wild larvae fed on taurine-rich organisms such as natural plankton $(12 \mathrm{mg} / \mathrm{g})$ and crustaceans $(20-30 \mathrm{mg} / \mathrm{g})$ [84]. With the aim of preventing a decrease in taurine content in the fish body, Takahashi et al. [85] attempted to enrich rotifers with taurine. They reported that taurine concentration in 
Table 1 Taurine content in live foods and dietary taurine requirements of various species of fish

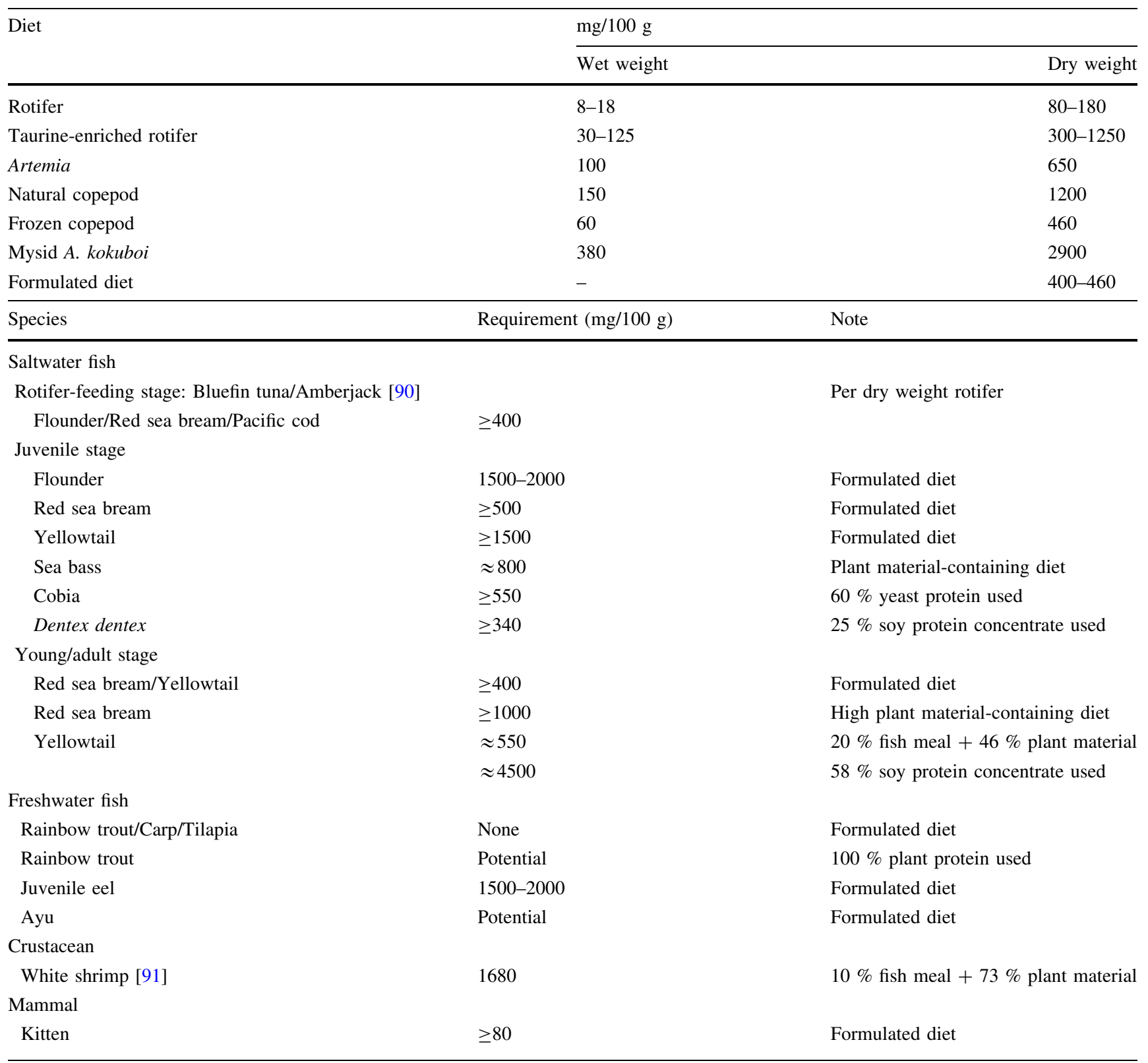

rotifer was in proportion to the amount of taurine added to a rotifer culture medium and the duration of enrichment. More specifically, the addition of taurine at a concentration of $400-800 \mathrm{mg} / \mathrm{L}$ to the rotifer culture medium resulted in the accumulation of taurine in rotifer at a concentration of $8-12 \mathrm{mg} / \mathrm{g}$ during an $18 \mathrm{~h}$ enrichment. This was the first successful attempt to introduce a free amino acid into live foods and was submitted for patent application [86]. Bivalve shellfish, such as oyster and scallop, have also been shown to directly absorb and accumulate taurine from water [87]. Feeding taurineenriched rotifer to newly hatched larvae of flounder, red sea bream, bluefin tuna, amberjack, and Pacific cod was also found to be effective for improving growth and survival. Moreover, in a fasting experiment, red sea bream fed taurine-enriched rotifer survived 3-4 days longer than those fed non-taurine-enriched rotifer, demonstrating a clear survival benefit (i.e., starvation tolerance) [88]. These results suggest that taurine is an essential nutrient for seawater fish larvae in the initial stage of seed production.

In summary, taurine has been identified as an important factor for improving the health and quality of larval and juvenile fish in seed production. The inclusion of 
inexpensive synthesized taurine in the list of designated feed additives in June 2009 has allowed for more effective use of this compound [89]. The taurine content in live foods and the dietary taurine requirements of various species of fish are summarized in Table 1 [90, 91].

\section{Conclusions}

This review of the last two decades of research on improving the quality and health of fish in seed production has focused on the advances made in our knowledge and use of certain nutrients, such as DHA, vitamin A derivatives, and taurine, which are important for the mass production of seedling of seawater fish. These nutritional research findings will help in our efforts to solve problems encountered in the field of seed production and improve seed production techniques.

Open Access This article is distributed under the terms of the Creative Commons Attribution License which permits any use, distribution, and reproduction in any medium, provided the original author(s) and the source are credited.

\section{References}

1. Worm B, Barbier EB, Beaumont N, Duffy JE, Folke C, Halpern BS, Jackson JBC, Lotze HK, Micheli F, Palumbi SR, Sala E, Selkoe KA, Stachowicz JJ, Watson R (2006) Impacts of biodiversity loss on ocean ecosystem services. Science 314:787-790

2. FAO (2012) The States of World Fisheries and Aquaculture, p 209

3. Watanabe T (1980) Seed production of fish and live food organisms. In: Ogino C (ed) Nutrition and feeding in fish. Koseisha-Koseikaku, Tokyo, pp 81-110 (in Japanese)

4. Hino A (1994) Seed production. In: Publication Committee of the Japanese Society of Fisheries Science (ed) Recent advances in fisheries science. Koseisha-Koseikaku, Tokyo, pp 124-131 (in Japanese)

5. Watanabe T, Kitajima C, Arakawa T, Fukusho K, Fujita S (1978) Nutritional quality of rotifer Brachionus plicatilis as a living feed from the viewpoint of essential fatty acids for fish. Nippon Suisan Gakkaishi 44:1109-1114 (in Japanese with English abstract)

6. Watanabe T, Oowa F, Kitajima C, Fujita S (1978) Nutritional quality of brine shrimp, Artemia salina, as a living feed from the viewpoint of essential fatty acids for fish. Nippon Suisan Gakkaishi 44:1115-1121 (in Japanese with English abstract)

7. Takeuchi T (2001) A review of feed development for early life stages of marine finfish in Japan. Aquaculture 200:203-222

8. Takeuchi T (1991) Variety of essential fatty acids requirement in fish. Kagaku Seibutu 29:571-580 (in Japanese)

9. Takeuchi T (1991) Nutritive deficiency and requirements in fish. In: Training project for sea farming in 1991-Textbooks of the basic theory course: v. development of fish in larval and juvenile stages series, No.4. Japan Sea Farming Association of Fisheries Agency, Tokyo, pp 1-68 (in Japanese)

10. Takeuchi $T$ (2009) Nutrition in fish larvae and juvenile. In: Watanabe $\mathrm{T}$ (ed) Nutrition and feeding in fish and crustaceans. Koseisha-Koseikaku, Tokyo, pp 204-228 (in Japanese)
11. Takeuchi T (1994) Retroconversion of DHA in live food. In: Report of the Grant-in-Aid for scientific research (No. 04806029): general research C (the 1992-1993 academic years). Ministry of Education, Tokyo, pp 1-30 (in Japanese)

12. Takeuchi T, Sugiura M, Tei H, Yamamoto Y, Watanabe T (1992) Enrichment of live food organisms with shark roes. In: Abstracts of the annual meeting of the Japanese Society of Fisheries Sciences. Japanese Society of Fisheries Sciences, Shimozaki, p 51 (in Japanese)

13. Takeuchi T, Zheng F, Yoseda K, Hirokawa J, Watanahe T (1994) Nutritive value of DHA-enriched rotifer for larval cod. Nippon Suisan Gakkaishi 60:641-652 (in Japanese with English abstract)

14. Ishizaki Y, Takeuchi T, Watanabe T, Shimizu K, Imaizumi K (1996) Rearing test of larval yellowtail fed with rotifers enriched with different levels of Vitamin $\mathrm{E}$ and different types of freezedried powder of shark roes. Suisanzoshoku 44:527-535 (in Japanese with English abstract)

15. Tanaka S (1998) Growth of artificially hatched eel larvae via feeding. Yoshoku 35(7):40-44 (in Japanese)

16. Takeuchi T (1997) Nutritional requirement for improvement of rearing seed production. In: Japanese Society of Fisheries Science (ed) Biology and Stock Enhancement of Japanese Flounder (Fisheries Science Series 112). Koseisha-Koseikaku, Tokyo, pp 96-106 (in Japanese)

17. Kanazawa A (1993) Nutritional mechanisms involved in the occurrence of abnormal pigmentation in hatchery-reared flatfish. J World Aquac Soc 24:162-166

18. Reitan KI, Rainuzzo JR, Olsen Y (1994) Influence of lipid composition of turbot larvae. Aquac Int 2:33-48

19. Satoh N, Takeuchi T (2009) Docosahexaenoic acid requirement of larval brown sole Pseudopleuronectes herzensteini. Nippon Suisan Gakkaishi 75:28-37 (in Japanease with English abstract)

20. Satoh N, Takaya Y, Takeuchi T (2009) Docosahexaenoic acid requirement for the prevention of abnormal morphology in brown sole Pseudopleuronectes herzensteini during D-E larval stages. Fish Sci 75:1259-1266

21. Satoh N, Takeuchi T (2011) Proof test of the rearing technique based on DHA requirement during larval period to prevent the morphological abnormalities in brown sole Pseudopleuronectes herzensteini. Sci Rep Hokkaido Fish Res Inst 80:25-31 (in Japanease with English abstract)

22. Uchida K, Kuwada H, Tsukamoto K (1993) Tilting behaviour, a fear response to frightening stimuli, as a possible predictive index for stocking effectiveness in the juveniles of red sea bream Pagrus major. Nippon Suisan Gakkaishi 59:991-999 (in Japanese with English abstract)

23. Furuta S, Watanabe T, Yamada H (1998) Predation by fishes on hatchery-reared Japanese flounder Paralichthys olivaceus juveniles released in the coastal area of Tottori prefecture. Nippon Suisan Gakkaishi 64:1-7 (in Japanese with English abstract)

24. Masuda R, Takeuchi T, Tsukamoto K, Ishizaki Y, Kanematsu M, Imaizumi K (1998) Critical involvement of dietary docosahexaenoic acid in the ontogeny of schooling behaviour in the yellowtail. J Fish Biol 53:471-484

25. Takeuchi T, Ishizaki Y, Masuda R (2000) Effect of DHA on development of brain and behavior in larval yellowtail. Yoshoku 37(13):114-117

26. Ishizaki Y, Uematsu K, Takeuchi T (2000) A preliminary study of the effect of dietary docosahexaenoic acid on the volumetric growth of the brain in larval yellowtail. Fish Sci 66:611-613

27. Ishizaki Y, Masuda R, Uematsu K, Shimizu K, Arimoto M, Takeuchi $T$ (2001) The effect of dietary docosahexaenoic acid on schooling behaviour and brain development in larval yellowtail. J Fish Biol 58:1691-1703

28. Masuda R, Takeuchi T, Tsukamoto K, Sato H, Shimizu K, Imaizumi K (1999) Incorporation of dietary docosahexaenoic 
acid into the central nervous system of the yellowtail Seriola quinqueradiata. Brain Behav Evol 53:173-179

29. Takeuchi T (2008) Seed production of Japanese spiny lobster Panulirus japonicus and common octopus Octopus vulgaris. Food Packag 49:510-518 (in Japanese)

30. Hamasaki K, Takeuchi T (2001) Dietary value of Artemia enriched with the $\omega$-Yeast or shark eggs as feed for planktonic larvae of Octopus vulgaris. Saibai Giken 28(2):65-68 (in Japanese with English abstract)

31. Shiraki M (2001) Incidence of common octopus Octopus vulgaris larvae caught by two-boat whitebait seine in the Naruto Straits of Tokushima Prefecture. Saibai Giken 29(1):55-57 (in Japanese with English abstract)

32. Okumura S, Kurihara A, Iwamoto A, Takeuchi T (2005) Improved survival and growth in Octopus vulgaris paralarvae by feeding large type Artemia and Pacific sandeel Ammodytes personatus. Aquaculture 244:147-157

33. Kurihara A, Okumura S, Iwamoto A, Takeuchi T (2006) Feeding Pacific sandeel enhances DHA level in common octopus paralarvae. Aquac Sci 54:413-420

34. Kurihara A (2008) Study on the searching effective nutrients in Artemia for common octopus Octopus vulgaris paralarvae. In: Doctoral thesis, Tokyo University of Marine Science and Technology, Tokyo (in Japanese)

35. Takeuchi T, Watanabe $T$ (1979) Effect of excess amounts of essential fatty acids on growth of rainbow trout. Nippon Suisan Gakkaishi 45:1517-1519 (in Japanese with English abstract)

36. Hamasaki K, Suprayudi MA, Takeuchi T (2002) Effects of dietary n-3 HUFA on larval morphogenesis and metamorphosis to megalops in the seed production of the mud crab, Scylla serrate (Brachyura:Portunidae). Suisanzoshoku 50:333-340

37. Suprayudi MA, Takeuchi T, Hamasaki K (2004) Effects of Artemia enriched with eicosapentaenoic and docosahexaenoic acid on survival and occurrence of melting failure in megalop larvae of the mud crab Scylla serrata. Fish Sci 70:650-658

38. Kaji S, Fukunaga T (1999) Results of a questionnaire on the recent status of seed production and market price of recaptured Japanese flounder Paralichthys olivaceus showing abnormal coloration. Saibai Giken 27:67-101 (in Japanese with English abstract)

39. Seikai T, Sinoda M (1981) Variations of frequency occurrence of color anormalies in hatchery-reared flounder Paralichthys olivaceus due to duration of Artemia salina fed. Bull Kyoto Inst Oceanic Fish Sci 5:29-37

40. Seikai T (1985) Influence of feeding periods of Brazilian Artemia during larval development of hatchery-reared flounder Paralichthys olivaceus on the appearance of albinism. Nippon Suisan Gakkaishi 51:521-527

41. Seikai T (1985) Reduction in occurrence frequency of albinism in juvenile flounder Paralichthys olivaceus hatchery-reared on wild zooplankton. Nippon Suisan Gakkaishi 51:1261-1267

42. Fukusho K, Nanba H, Yamamoto T, Yamasaki Y, Lee MT, Seikai T, Watanabe T (1987) Reduction of albinism in juvenile flounder Paralichthys olivaceus hatchery-reared on fertilized eggs of red sea bream Pagrus major, and its critical stage for the effective feeding. Bull Nat Res Inst Aquac 12:1-7 (in Japanese with English abstract)

43. Miki N, Taniguchi T, Hamakawa H (1989) Adequate vitamin level for reduction of albinism in hatchery-reared hirame Paralichthys olivaceus fed on rotifer enriched with fat-soluble vitamins. Suisanzoshoku 37:109-114 (in Japanese with English abstract)

44. Miki N, Taniguchi T, Hamakawa H, Yamada Y, Sakurai N (1990) Reduction of albinism in hatchery-reared flounder "Hirame" Paralichthys olivaceus by feeding on rotifer enriched with vitaminA. Suisanzoshoku 38:147-155 (in Japanese with English abstract)

45. Yamamoto S, Oda M (1993) Effects of lipid-soluble vitamins on the reduction of colour abnormalities of juvenile flounders
Paralichthys olivaceus. Bull Fish Expt Stn Okayama Pref 8:1-4 (in Japanese)

46. Takeuchi T, Haga Y (2000) Effect of vitamin on pigmentation and morphological abnormality in Japanese flounder Paralichthys olivaceus. Kagaku Seibutu 38:728-731 (in Japanese)

47. Minami T (1982) The early life history of a flounder Paralichthys olivaceus. Nippon Suisan Gakkaishi 48:1581-1588 (in Japanese with English abstract)

48. Seikai T, Shimozaki M, Watanabe T (1987) Estimation of larval stage determining the appearance of albinism in hatchery-reared juvenile flounder Paralichthys olivaceus. Nippon Suisan Gakkaishi 53:1107-1114

49. Takeuchi T, Tarui F (2005) Inducement of malformation to Japanese flounder by relative vitamin A compounds, especially retinoic acid. Aquabiology 27:400-403 (in Japanese)

50. Dedi J, Takeuchi T, Seikai T, Watanabe T (1995) Hypervitaminosis and safe levels of vitamin A for larval flounder Paralichthys olivaceus fed Artemia nauplii. Aquaculture 133:135-146

51. Dedi J, Takeuchi T, Seikai T, Watanabe T, Hosoya K (1997) Hypervitaminosis A during vertebral morphogenesis in larval Japanese flounder. Fish Sci 63:466-473

52. Takeuchi T, Dedi J, Haga Y, Seikai T, Watanabe T (1998) Effect of vitamin A compounds on bone deformity in larval Japanese flounder Paralichthys olivaceus. Aquaculture 169:155-165

53. Tarui F, Haga Y, Ohta K, Shima Y, Takeuchi T (2006) Effect of Artemia nauplii enriched with vitamin A palmitate on hypermelanosis on the blind side in juvenile Japanese flounder Paralichthys olivaceus. Fish Sci 72:256-262

54. Haga Y, Tarui F, Okumura K, Shima Y, Takeuchi T (2006) Effects of light irradiation on the dynamics of vitamin A compounds in rotifers and Artemia. Fish Sci 72:1020-1026

55. Haga Y, Takeuchi T, Seikai T (1999) Effect of retinoic acid on larval Japanese flounder Paralichthys olivaceus reared on Artemia nauplii. Suisanzoshoku 47:559-566

56. Haga Y, Takeuchi T, Seikai T (2002) Influence of all-trans retinoic acid on pigmentation and skeletal formation in larval Japanese flounder. Fish Sci 68:560-570

57. Miwa S, Yamano K (1999) Retinoic acid stimulates development of adult-type chromatophores in the flounder. J Exp Zool 284:317-324

58. Haga Y, Suzuki T, Takeuchi T (2002) Retinoids as potent teratogens on larval development of Japanese flounder Paralichthys olivaceus. Fish Sci 68:789-792

59. Haga Y, Takeuchi T, Seikai T (2004) Changes of retinoids contents in larval Japanese flounder Paralichthys olivaceus and Artemia nauplii enriched with a large dose of all-trans retinoic acid. Fish Sci 70:436-444

60. Hasegwa Y, Takeuchi T, Itagaki E, Fukunaga T (1998) Relationship between fat soluble vitamins in diet and the occurrence of colour abnormality on the blind side of juvenile Japanese flounder. Suisanzoshoku 46:279-286 (in Japanese with English abstract)

61. Yoo JH, Takeuchi T, Seikai T (2000) Sensitivity of the metamorphic events and morphogenesis of Japanese flounder Paralichthys olivaceus during larval development to thyroxine. Fish Sci 66:846-850

62. Murayama Y, Takeuchi T (2004) Effect of vitamin D enriched feed and bottom. In: Sea ranching technology series No.10. Fisheries Research Agency, Tokyo, pp 95-100 (in Japanese)

63. Suzuki T, Kurokawa T (2000) Organogenesis in flounder. Protein, nucleic acid and enzyme 45:86-92 (in Japanese)

64. Hamre K, Krossøy C, Lock EJ, Moren M (2010) Roles of lipidsoluble vitamins in the ontogeny of marine fish larvae. Aquac Res 41:745-750

65. Takeuchi T, Matunari H (2008) Taurine. In: Nishigawa K (ed) Science of functional food. Technology Research Service Center. Tokyo, pp 1134-1136 (in Japanese) 
66. Yokoyama M, Takeuchi T, Park GS, Nakazoe J (2001) Hepatic cysteine sulphinate decarboxylase activity in fish. Aquac Res 32:216-220

67. Goto T (2002) Variety of taurine biosynthetic pathway in fish. Kagaku Seibutu 40:635-637 (in Japanese)

68. Park GS, Takeuchi T, Yokoyama M, Seikai T (2002) Optimal dietary taurine level for growth of juvenile Japanese flounder Paralichthys olivaceus. Fish Sci 68:824-829

69. Matsunari H, Furuita H, Yamamoto T, Kim SK, Sakakura Y, Takeuchi T (2008) Effect of dietary taurine and cystine levels on growth performance and feeding behavior of red sea bream Pagrus major. Aquaculture 274:142-147

70. Walton MJ, Cowey CB, Adron JW (1982) Methionine metabolism in rainbow trout fed diets of differing methionine and cystine content. J Nutr 112:1525-1535

71. Sakaguchi M, Murata M (1988) Taurine. In: Sakaguchi M (ed) Extractive components of fish and shellfish. Koseisha-Koseikaku, Tokyo, pp 56-65 (in Japanese)

72. Yokoyama M, Nakazoe J (1992) Accumulation and excretion of taurine in rainbow trout Oncorhynchus mykiss fed diets supplemented with methionine, cystine and taurine. Comp Biochem Physiol 102A:565-568

73. Seikai T, Kinoshita I (1994) Comparative study on growth and development between the wild fish and the hatchery fish. In: Summary of research results of production techniques of healthy fish larvae in 1993. Fisheries Agency. Tokyo, pp 141-160 (in Japanese)

74. Seikai T, Takeuchi T, Park GS (1997) Comparison of growth, feed efficiency and chemical composition of juvenile flounder fed live mysids and formula feed under laboratory conditions. Fish Sci 63:520-524

75. Park GS, Takeuch T, Seikai T, Nakazoe J (1997) Nutritional study on mysids as food organisms for juvenile Japanese flounder. Suisanzoshoku 45:371-378 (in Japanese with English abstract)

76. Park GS, Takeuchi T, Seikai T, Yokoyama M (2000) The effects of residual salts and free amino acids in mysid meal on growth of juvenile Japanese flounder Paralichthys olivaceus. Nippon Suisan Gakkaishi 66:697-704 (in Japanese with English abstract)

77. Furuta S (1993) Releasing techniques and fry quality. In: Kitajima C (ed) Healthy fry for release, and their production techniques. Koseisha-Koseikaku, Tokyo, pp 94-101 (in Japanese)

78. Knopf K, Sturman JA, Armstrong M, Hayes KC (1978) Taurine: an essential nutrient for the cat. J Nutr 108:773-778

79. Kim SK, Takeuchi T, Yokoyama M, Murata Y, Kaneniwa M, Sakakura Y (2005) Effect of dietary taurine levels on growth and feeding behavior of juvenile Japanese flounder Paralichthys olivaceus. Aquaculture 250:765-774
80. Goto T, Takagi S, Ichiki T, Sakai T, Endo M, Yoshida T, Ukawa M, Murata H (2001) Studies on the green liver in cultured red sea bream fed low level and non-fish meal diets: relationship between hepatic taurine and biliverdin levels. Fish Sci 67:58-63

81. Kim SK, Matsunari H, Nomura K, Tanaka H, Yokoyama M, Murata Y, Ishihara K, Takeuchi T (2008) Effect of dietary taurine and lipid contents on conjugated bile acid composition and growth performance of juvenile Japanese flounder Paralichthys olivaceus. Fish Sci 74:875-881

82. Takagi S, Murata H, Goto T, Endo M, Yamashita H, Ukawa M (2008) Taurine is a essential nutrient for yellowtail Seriola quinqueradiata fed non-fish meal diets based on soy protein concentrate. Aquaculture 280:198-205

83. Matsunari H, Yamamoto T, Kim SK, Goto T, Takeuchi T (2008) Optimum dietary taurine level in casein-based diet for juvenile red sea bream Pagrus major. Fish Sci 74:347-353

84. Matsunari H, Takeuchi T, Tamura Y, Takahashi M, Ishibashi N, Chuda H, Arakawa T (2003) Changes in the taurine content during the early growth stages of artificially produced yellowtail compared with wild fish. Nippon Suisan Gakkaishi 69:757-763 (in Japanese with English abstract)

85. Takahashi T, Amano T, Takeuchi T (2005) Establishment of direct enrichment method of taurine to rotifer. Aquac Sci 53:121-126 (in Japanese with English abstract)

86. Takahashi T, Amano T, Takeuchi T (2003) Taurine directly enriched rotifer. J-Patent 2003-259760 (in Japanese)

87. Takeuchi $\mathrm{T}$ (2005) Recent development of on amino acids and peptides research in fish. In: Reports of the Research Committee of Essential Amino Acids (Japan); No. 174, pp 9-17 (in Japanese)

88. Chen JN, Takeuchi T, Takahashi T, Tomoda T, Koiso H, Kuwada $\mathrm{H}$ (2004) Effect of rotifers enriched with taurine on growth and survival activity of red sea bream Pagrus major larvae. Nippon Suisan Gakkaishi 70:542-547 (in Japanese with English abstract)

89. Takeuchi T (2010) Synthetic taurine is a good healthy supplement for fish. Nippon Suisan Gakkaishi 76:298-303 (in Japanese)

90. Matsunari $\mathrm{H}$, Hashimoto $\mathrm{H}$, Iwasaki $\mathrm{T}$, Oda $\mathrm{K}$, Masuda $\mathrm{Y}$, Imaizumi H, Teruya K, Furuita H, Yamamoto T, Hamada K, Mushiake K (2013) Effect of feeding rotifers enriched with taurine on the growth and survival of larval amberjack Seriola dumerili. Fish Sci 79:815-821

91. Yue YR, Lin YJ, Tian LX, Yang HJ, Liang GY, He JT (2013) The effect of dietary taurine supplementation on growth performance, feed utilization and taurine contents in tissues of juvenile white shrimp Litopenaeus vannamei Boone, 1931, fed with lowfishmeal diets. Aquac Res 44:1317-1325 